\title{
Optimal durability in least life cycle cost methods: the case of LED lamps
}

\author{
Jessika Luth Richter • Robert Van Buskirk • \\ Carl Dalhammar $\cdot$ Peter Bennich
}

Received: 26 October 2017 / Accepted: 8 April 2018/Published online: 29 April 2018

(C) The Author(s) 2018

\begin{abstract}
In the European Union (EU), mandatory durability ecodesign requirements have recently been set for some products, including lighting products; further development of durability standards is also expected in the future. Durability standards can bring environmental and consumer benefits, but the question remains about what optimal durability is. In this paper, the product lifetime aspect of durability is considered, and optimal lifetimes in relation to least life cycle cost (LCC) for the consumer are analysed. The paper focusses the analysis on a case of LED lamps available in an online market in December 2016 and models optimal lifetimes from an LCC perspective. The statistical error of the regression does not allow for calculation of the optima with precision, but the calculation indicates optimal
\end{abstract}

\author{
J. L. Richter $(\bowtie) \cdot$ C. Dalhammar \\ International Institute for Industrial Environmental Economics, \\ Lund University, PO Box 196, 22100 Lund, Sweden \\ e-mail: jessika.luth.richter@iiiee.lu.se \\ C. Dalhammar \\ e-mail: carl.dalhammar@iiiee.lu.se
}

R. Van Buskirk

Enervee, 2100 Abbot Kinney Blvd, Unit D, Venice, CA 90291, USA

e-mail: robertvb@enervee.com

P. Bennich

The Swedish Energy Agency, Box 380 69, S-100 64 Stockholm, Sweden

e-mail: peter.bennich@energimyndigheten.se lifetime is close to 25,000 hours. The influence of smaller discount rates and more intensive use of the product are also modelled, which indicate that durability is desirable in intense-use scenarios in particular. The usefulness of the method is discussed and the findings are compared to previous literature and studies examining durability and increased lifetimes for products, including those using an alternative approach of life cycle assessment (LCA). The initial results of this LCC method indicate that longer lifetimes than those currently required by legal standards in the EU could be appropriate for LED lamps. As such, the advantages and disadvantages of different policy instruments to stimulate increased durability are also discussed. The paper concludes with suggestions for potential future research and further policy development.

Keywords Durability P Product lifetime - Lifecycle cost . Ecodesign standards $\cdot$ Light-emitting diode (LED) lamps · Product policy $\cdot$ Circular economy $\cdot$ Resource efficiency Planned obsolescence $\cdot$ Ecodesign directive

\section{Introduction}

One of the substantial policy developments related to the circular economy is the interest for incentivising more durable products (European Commission 2016). Durability refers to the "ability of a product to perform its function at the anticipated performance level over a given period (number of cycles/uses/ 
hours), under the expected conditions of use and under foreseeable actions" (Boulos et al. 2015, p. 4). This interest has been manifested in several policies and initiatives already, including national schemes to promote product repairs. Public procurers in some countries have started to purchase remanufactured furniture and remanufactured IT products, and there is a general interest in promoting product durability in public procurement (Montalvo et al. 2016). France has banned planned obsolescence and set up incentives for manufacturers to provide spare parts (Maitre-Ekern and Dalhammar 2016). Iceland and Norway have extended the limitation period for legal guarantees of products from 2 to 5 years and strengthening lifespan legal guarantees is being investigated across the EU (Tonner and Malcolm 2017). It has been argued that durability information should be also be included in the mandatory EU energy labelling scheme (Burrows 2016; RREUSE 2015; ENDS 2016). This is contested, however, and an alternative approach is to make use of voluntary labelling to promote information about product durability (European Parliament 2017). Mandatory ecodesign durability requirements have recently been set for vacuum cleaners and lighting products through EU regulations ${ }^{1}$ under the EU Ecodesign Directive, ${ }^{2}$ and it is expected that more product groups will follow in the future. In general, the various initiatives reflect growing momentum and debate about how resource efficiency should be addressed through policy interventions. While there are a few different policy options to address durability, there is one central question for policy development moving forward: what durability is desirable for different products?

In this paper, the case of lighting products, one of the first product groups to have mandatory minimum durability requirements, is examined to investigate the question of optimal durability, with a focus on the lifetime

\footnotetext{
${ }^{1}$ Regulation 666/2013/EU of 8 July 2013 Implementing Directive 2009/125/EC of the European Parliament and of the Council with Regard to Ecodesign Requirements for Vacuum Cleaners, [2013] OJ L192/24 and Regulation 1194/2012 of 12 Dec 2012 Implementing Directive 2009/12/EC of the European Parliament and of the Council with Regard to Ecodesign Requirements for Directional Lamps, Light Emitting Diode Lamps and Related Equipment, [2012] OJ L342/1

${ }^{2}$ Directive 2009/125/EC of the European Parliament and of the Council 21 October 2009 establishing a framework for the setting of ecodesign requirements for energy-related products, OJ 2009 L 298/ 10.
}

aspect. The EU Ecodesign regulations on lighting prod$\mathrm{ucts}^{3}$ have set functionality requirements relating to nondirectional and directional lamps. Most of the requirements refer to dimensions that influence the lifetime of the lamps. Lifetime, as used in a declaration by a manufacturer, is defined in Appendix II in the Regulation $1194 / 2012$ and is a combination of remaining luminous flux and survival factor:

'lamp lifetime' means the period of operating time after which the fraction of the total number of lamps which continue to operate corresponds to the lamp survival factor of the lamp under defined conditions and switching frequency. For LED lamps, lamp lifetime means the operating time between the start of their use and the moment when only $50 \%$ of the total number of lamps survive or when the average lumen maintenance of the batch falls below $70 \%$, whichever occurs first.

EU ecodesign requirements for LED lamps relate to measurements made at 6000 hours (250 days), at which the remaining luminous flux has to be $\geq 80 \%$, and the lamp survival factor $\geq 90 \%$, both based on statistical averages. The requirements do not go beyond the 6000-h measurement for practical reasons of time and capacity for such tests and because the dynamic nature of the LED market (as with many electronic products) can create challenges for testing and market surveillance (VITO and VHK 2015a, b). Shorter testing times would be preferred, but this can be a trade-off with reliable testing methods for durability (Narendran et al. 2016). This being said, there are also positive developments in accelerated testing methods that may help to address these issues (Narendran et al. 2016; Narendran, personal communication, 3 March 2017) and some jurisdictions like California are working with a combination of lumen maintenance and "time to failure" tests to set requirements for minimum rated lifetimes of

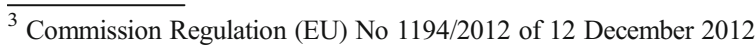
implementing Directive 2009/125/EC of the European Parliament and of the Council with regard to ecodesign requirements for directional lamps, light emitting diode lamps and related equipment; and Commission Regulation (EC) No 244/2009 of 18 March 2009 implementing Directive 2005/32/EC of the European Parliament and of the Council with regard to ecodesign requirements for nondirectional household lamps
} 
10,000-25,000 hours, depending on the LED lamp type (California Energy Commission 2016). ${ }^{4}$

Currently, several manufacturers are promoting the long life of LED lamps as a valuable attribute to consumers, with many now sold claiming lifetimes exceeding 50,000 hours (Hixon 2012); however, there is also speculation that lifetimes for LED lamps may be decreasing in the future if business models for longer life products are not viable (MacKinnon 2016). While prolonging product lifetimes and durability is argued to have environmental benefits (Casamayor et al. 2015; Dzombak et al. 2017; Hendrickson et al. 2010), it is important to also consider any trade-offs in terms of costs for consumers and environmental impacts. Before additional policies should be considered concerning lifetimes for lighting products, there needs to be further exploration of what are optimal lifetimes for these products. One approach to determining if longer lifetimes are desirable is a life cycle cost (LCC) approach (i.e. calculating the costs for a consumer over the lifetime of the product - see methodology).

The aim of this paper is to present a practical method for determining optimal lifetime from an LCC approach and discuss the findings in context of potential policy inventions for promoting durability. The LCC methodology for analysing optimal lifetimes for LED lamps is first described, followed by the results of the analysis. The results from the LCC analysis are discussed in relation to previous LCC studies on other products and also in relation to life cycle assessment (LCA) studies examining lifetimes for LED lamps. Lastly, relevant policies for addressing product lifetimes for lighting products are discussed and recommendations made for future research and policy development.

\section{Accounting for durability in LCC methods}

Previous research has utilised LCC methods to determine when durability is optimal by constructing cases of conventional versus durable product options (also focussing on the lifetime aspect). In their study of refrigerators and ovens, Boulos et al. (2015) found

\footnotetext{
${ }^{4}$ The test procedures are found in 10 C.F.R. 430.23(ee) (Appendix BB to Subpart B of Part 430) https://www.gpo.gov/fdsys/pkg/CFR-2017title10-vol3/pdf/CFR-2017-title10-vol3-part430-subpartB-appBB.pdf
}

that generally the more durable products yielded a lower LCC compared to the standard product scenario, primarily due to the avoided cost of the replacement product. Other comparative LCC studies for LED street lighting showed that even with increased efficacy and falling prices of lighting products, delaying purchase of replacements could still be advantageous from an LCC perspective; this is attributed to the large role of the purchase price in the LCC (see Ochs et al. 2014; Tähkämö et al. 2016). Another LCC study of $800-1 m$ household LED lamps by Richter et al. (2017) constructed multiple scenarios with variables of increasing efficiency of LED technology, decreasing purchase price and high or low electricity prices. The LCC for the 10,000-, 20,000and 30,000-h lamps were compared. The study confirmed the significance of the initial purchase price and found shorter lifetimes were preferred when there were significant improvements in both efficacy (i.e. at least 30\% higher) and purchase prices (at least $10 \%$ lower) or moderate improvements in the context of high energy cost. ${ }^{5}$

The previous LCC approaches with comparative cases illustrated how the different factors influence LCC; however, the results are constrained to the assumptions made in the individual cases as well as assumptions about future choices by consumers in replacing products. For example, scenarios of improved efficacy and price assume consumers will take advantage of these factors when buying replacement products. Lastly, scenario-based LCC answers the question of under which conditions longer lifetimes may be preferable, but do not necessarily give a more specific indication of optimal lifetimes and for an overall consumer market for the product.

In contrast to previous research on optimal lifetimes, the main objective of this study was not to develop scenarios for LCC, but rather to track the role of durability (focussing on lifetime) based on a snapshot of a current LED market. Web crawling techniques for tracking attributes in a market have been proposed as a way to generate data to effectively calculate and track LCC for product markets (Van Buskirk 2015; Bennich et al. 2017). Similarly, the research presented in this paper analysed web crawled market data, using an LCC methodology

\footnotetext{
$\overline{5}$ The study used $0.3 €$ in Denmark as the high energy cost point.
} 
to then determine optimal lifetimes for LED lamps in a market.

\section{LCC methodology}

In the preparatory studies for the lighting product ecodesign standards (VITO and VHK 2015a), LCC for base cases were calculated as:

$L C C=P P+P W F \times O E+E o L$

where $L C C$ is life cycle costs, $P P$ is the purchase price, $O E$ is the operating expense, $P W F$ is present worth factor, which is a factor of the product life and the discount rate and $E O L$ are the end of life costs.

Similar to the EU Methodology for Ecodesign of Energy-related Products, ${ }^{6}$ this paper defines LCC as:

$$
\mathrm{LCC}=\mathrm{P}_{\mathrm{A}}+\mathrm{PWF} \cdot \mathrm{P}_{\mathrm{E}} \cdot \mathrm{UEC}
$$

where $P_{A}$ is the appliance price, $P W F$ is the present worth factor, $P_{E}$ is the price of electricity and $U E C$ is the annual unit energy use. End of life costs are excluded from this analysis as they constitute a very small portion of the LCC for LED lighting products ${ }^{7}$ and these costs are likely incorporated in the purchase price for EU countries where the WEEE Directive applies.

The LCC has a dependence on durability because of the relationship between lifetimes (L) and the present worth factor (PWF), in which the durability of a product determines the lifetime. The relationship between PWF and lifetime is provided by the following equation:

PWF $=\frac{1-(1+\mathrm{i})^{-\mathrm{L}}}{\mathrm{i}}$

Where $i$ is the interest or discount rate and $L$ is the product lifetime. If the model is optimised to minimise LCC (applying an LCC optimisation regression method from Van Buskirk et al. 2014 ${ }^{8}$ ), both PWF and UEC are optimised. Under UEC optimisation,

\footnotetext{
${ }^{6}$ This methodology can be found at https://ec.europa. eu/docsroom/documents/ $10024 /$ at tachments / 1 /translations/en/renditions/pdf.

${ }^{7}$ For example, approximately $€ 0.04$ per LED is the end of life cost charged to producers in the Danish EPR system based indicative fees charged by a Lighting Producer Responsibility Organization; see www. lwf.nu.

${ }^{8}$ LCC optimization method is only briefly presented here; for a full explanation, please refer to supplementary data ("Supporting Information") which can be accessed online in Van Buskirk et al. (2014).
}

UEC decreases with increasing PWF, which in turn increases with lifetime.

Dividing by the PWF (which takes into account the influence of inflation and discount rates) gives the annualised LCC:

$\frac{L C C}{P W F}=\frac{P_{A}}{P W F}=+P_{E} \cdot U E C$

Annualised LCC measures the costs of the lamps that may occur every year (taking into account that these are not regular). The focus is on the change in $\mathrm{P}_{\mathrm{A}} / \mathrm{PWF}$ with respect to the lifetime in hours. To do this, the LED models in the data were binned into four categories: $\leq$ $15,000,20,000,25,000$ and $\geq 30,000$ hours and the price regression coefficients for each bin were calculated for a selected subset of LED lamps.

The regression results were then used to calculate $\mathrm{P}_{\mathrm{A}} /$ PWF as a function of lifetime. PWF is also dependent on the intensity of operation, so PWFs for three different consumer use scenarios, based on hours of operation per year-1000, 2000 and 4000 - were considered. Then, $\mathrm{P}_{\mathrm{A}} / \mathrm{PWF}$ was calculated for each of the cases, yielding three curves for the 1000, 2000 and 4000 hours per year as well as the minima (i.e. optimal cost points) for the 1000, 2000 and 4000 hours/year use scenarios, respectively. While the effect of energy use (UEC) is not modelled, the implications of the model in relation optimising LCC with respect to UEC are discussed. The method described above assesses the optimum lifetime for the entire market studied, accounting for the product attributes of total lumen output, lumens/watt efficacy and colour temperature.

Data

The data used for the regression analysis were 344 LED products on the online market in Sweden and Denmark in December 2016, focussing on the most common category of LED retrofit lamps for households ("klot" in Swedish or "A" lamps) with E27, E14 and B22 bases. To construct the dataset, web crawling was used, which is a technique for extracting information from websites, transforming unstructured data on the web into a structured dataset (i.e. Excel sheet with features including brand (masked), price, lumen output, power, colour rendering index, temperature, among others) (see Van Buskirk and Richter 2017). Such methods have been applied to price monitoring and calculation of learning 
Table 1 Data characteristics for LED lamps in each lifetime category (Van Buskirk and Richter 2017)

\begin{tabular}{lllll}
\hline Lifetime & $\leq 15,000 \mathrm{~h}(n=130)$ & $20,000 \mathrm{~h}(n=45)$ & $25,000 \mathrm{~h}(n=139)$ & $\geq 30,000(n=30)$ \\
\hline Price $(€$ based on 1SEK = €0.105) & AVG, 13 & AVG, 15.7 & AVG, 14.25 & AVG, 15.2 \\
& Range, 3-100.7 & Range, 0.95-68.1 & Range, 2-75.6 & Range, 2-41 \\
Luminous flux $(\mathrm{lm})$ & AVG, 475 & AVG, 489 & AVG, 573 & AVG, 455 \\
& Range, 8-1800 & Range, 110-2200 & Range, 136-1522 & Range, 82-1500 \\
& AVG, 83 & AVG, 72 & AVG, 79 & AVG, 68 \\
Efficiency $(\mathrm{lm} / \mathrm{W})$ & Range, 16-128 & Range, 37-100 & Range, 46-125 & Range, 27-120 \\
Correlated colour temperature $(\mathrm{CCT})(\mathrm{K})$ & AVG, 2700 & AVG, 2850 & AVG, 2700 & AVG, 3000 \\
& Range, 1900-6500 & Range, 1800-6500 & Range, 2100-6500 Range, 2700-6000 \\
\hline
\end{tabular}

curves for LED household lamps (see Gerke et al. 2015), as well as monitoring of general attributes of a given product market over time (Bennich et al. 2017). Similar to the method used by Gerke et al. (2015), the dataset was cleaned to consider household lamps for which there was data for sale price, luminous flux, wattage and correlated colour temperature (CCT).

The products in the dataset were binned into four lifetime groups for analysis. Other characteristics of the LED products in the dataset are shown in Table 1.

The dataset showed a correlation between price and luminous flux, a weak correlation with CCT, but no significant correlation with efficiency or lifetime. ${ }^{9}$ Gerke et al.'s (2015) study of LED lamps also found that brand names play a role in the price of LED lamps. A lack of relationship between price and efficiency has been highlighted as problematic in using LCC to set MEPS (see Siderius 2013) and the relationship between the lifetime and LCC is further discussed later in this paper.

\section{Optimal lifetimes for LED lamps}

The results of the modelling for optimal lifetimes in the three use scenarios are shown in Fig. 1. This modelling focusses on the optimisation of the PWF in optimisation of LCC and shows lifetime related to the price/present worth factor. The " $\mathrm{x}$ " marks the minimum of the curves, or the lowest value for $\mathrm{P}_{\mathrm{A}} / \mathrm{PWF}$, which then corresponds to the optimal lifetime for each scenario of yearly use. Assuming other factors of the LCC are also optimised (e.g. energy use), these lifetimes would in turn yield the

\footnotetext{
${ }^{9}$ The Pearson's correlation coefficient analysis was conducted with the dataset in SPSS considering a 0.05 significance level.
}

optimised or least LCC. The statistical error of the regressions does not allow for calculation of the optima with precision, but the calculation is illustrative that optimal lifetime for this range of LED lamps is close to 25,000 hours, with slightly longer lifetimes optimal the more intensely they are used. For comparison, the average lifetime for the data modelled in the sample is approximately 21,500 hours.

In this analysis, a discount rate of $6 \%$ was used in the calculation. Different assumptions about the interest or discount rates shift the $\mathrm{P}_{\mathrm{A}} / \mathrm{PWF}$, favouring slightly longer lifetimes with a smaller discount rate and shorter lifetimes with a high discount rate (as shown in Fig. 2), in relation to the base case with $6 \%$ (as shown in Fig. 1). The effect of the discount rate is on the $\mathrm{P}_{\mathrm{A}} / \mathrm{PWF}$ ratio. $\mathrm{A}$ lower discount rate leads to a lower LCC/PWF while a higher discount rate leads to a higher $\mathrm{P}_{\mathrm{A}} / \mathrm{PWF}$. Furthermore, the less intense use, the higher the impact of the discount rate on the shift of the optimal LCC point towards shorter lifetimes. It is also noted that for low intensities of use, the annualised price is roughly constant for different lamp lifetimes. Lamp lifetime has the largest impact on optimal LCC in the higher intensity use scenarios.

\section{Discussion}

\section{LCC approach}

Our findings are in line with previous LCC product studies of appliances and street lighting that found generally more durable products yield a lower LCC compared to a standard product scenario (Boulos et al. 2015; Ochs et al. 2014; Tähkämö et al. 2016). However, the model does not capture the opportunity costs of longer 
Fig. 1 Model approximating optimum lifetimes (marked with $\mathrm{x}$ ) for different scenarios of use

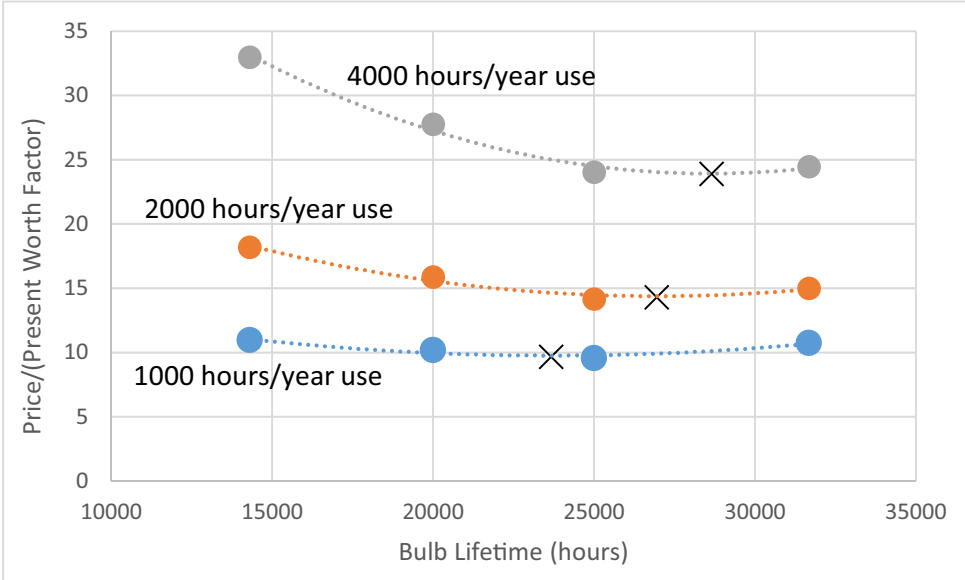

lifetimes (e.g. savings from more efficient replacement products). As the Richter et al. (2017) scenario-based approach demonstrated, however, these costs may only matter in certain scenarios in which there are significant improvements with price and efficiencies. Significant price improvements with household LED lamps may be unlikely after 2025, according to U.S. Department of Energy predictions (Navigant 2016). Efficacy improvements may still be possible, but it is also clear from the dataset in this study that there are a range of efficacies available to consumers, and if this parameter is not influential in their purchasing decisions (Rodemeier et al. 2017), consumers may not be buying products with the least LCC. This also suggests that optimal lifetime needs to be considered in the context of its relationship to other parameters in the LCC equation.

It should also be considered that the lifetimes in the modelling for LED lamps are the rated (i.e. stated) lifetimes supplied by the producers in selling the products on the market. In reality, actual lifetimes may differ
(Casamayor et al. 2015). However, there is little information yet on whether actual lifetimes for LED lamps differ greatly from the rated lifetimes and at present the rated lifetime is also the only information for consumers to incorporate this dimension in life cycle costing.

In theory, optimum LCC policies should move markets to an optimum where there are specific relationships between price, energy use, cost of energy and PWF (and by implication lifetimes and durability). Returning to the original equation for LCC (S2), it shows that in an optimised LCC, there is a direct synergy between smaller energy use and increased lifetime under LCC optimisation through the relationship between PWF (with lifetime implicit) and UEC (annual unit energy use).

If minimum standards on durability increase product lifetimes relative to an unregulated market, the increase in product lifetime increases PWF. In calculating optimum LCC with respect to energy use, higher values of PWF imply lower values of UEC at LCC optimum. In
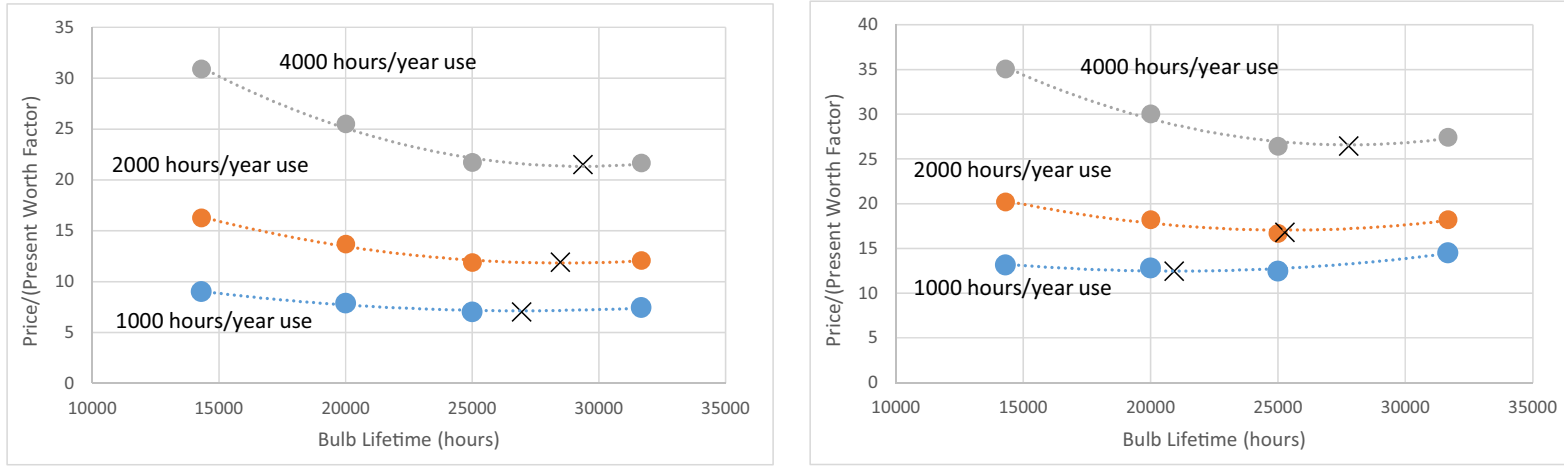

Fig. 2 Model with discount rates of $3 \%$ (left) and $9 \%$ (right). The " $x$ " corresponds to the minimum of the quadratic trend line fit for each curve 
other words, solving market imperfections for this parameter can increase lifetime, which in turn leads to increased product efficiency for LCC-optimised MEPS. This implies that durability standards can indirectly have an effect on climate change mitigation by allowing for LCC-optimised efficiency standards to become more stringent. This also implies a benefit to optimising lifetimes for both consumers and society.

Tracking optimal lifetimes with the method introduced in this paper can be easily implemented as a regular part of monitoring and analysis of product markets. As the case of LED lamps has demonstrated, this method is useful for monitoring how the optimal lifetime in a market compares to the average lifetime in the market. With real-time monitoring, the market average lifetime and optimal lifetime can also be tracked over time to show trends and changes. The case of LED lamps in the Swedish online marketplace demonstrated that the optimal lifetime may be higher than the average, suggesting a role for policies to push or pull the market in towards longer lifetimes and optimal LCC.

\section{LCA approach}

Longer product lifetimes have potential environmental benefits as well as consumer benefits. To consider this, the LCC approach can be complemented with an LCA approach, which can identify environmental impacts associated with durability. Studies considering optimal product lifetimes from an LCA perspective (looking at full range of impacts, or in some cases only energy demand) have demonstrated that longer product lifetimes can be preferred for some product groups, particularly when the environmental impacts in the extraction, production and waste phases are the most significant; this generally applies for ICT products (Bakker et al. 2012; Cooper and Gutowski 2015). For these products, extension of lifetime may be positive even if the technology is becoming more energy efficient (Bakker et al. 2014; EU Commission 2015; Prakash et al. 2015; VHK 2014). However, for energy-using products for which the majority of life cycle impacts occur in the use phase, studies have indicated that increased durability may not be preferred to replacement with more efficient products (Boulos et al. 2015; Cooper and Gutowski 2015; Gutowski et al. 2011).

Tähkämö et al. (2013) examined the role of lifetime in influencing the overall environmental impact for the case of an LED downlight luminaire. The authors found that the average environmental impact of a luminaire with 50,000 hours useful life was $34 \%$ lower (with a range of 2-70\% among different impact categories) and 36,000 hours useful life was $23 \%$ lower (1-47\%) compared to 15,000 hours useful life. The difference in impacts varied depending on what impacts were being considered, with the largest differences evident in the waste categories (both hazardous and non-hazardous) and the smallest in the primary energy. ${ }^{10} \mathrm{~A}$ more recent LCA also confirmed the findings of greater overall environmental impacts associated with shorter lifespans for LED lamps (see Casamayor et al. 2017).

A review of several LCAs of lamps, including LED lamps, found that the energy consumption in the use phase generally dominates the total life cycle environmental impacts (Tähkämö and Dillon 2017). However, certain factors can influence the distributions, including lifetimes. Tähkämö et al. (2013) also found that the shorter the LED lifetime, the larger the share of manufacturing in the total life cycle impacts (due to the need for manufacturing additional replacement lamps), as shown in Fig. 3. The results of the Tähkämö et al. (2013) study were confirmed in a more recent comparative LCA for LED lighting products, which also considered an even shorter scenario of 1000 hours lifetime (compared to 15,000 and 40,000 hours lifetimes) (Casamayor et al. 2017). Not only did the assumption of shorter lifetimes result in significantly higher impacts of both LED products considered, but it also resulted in the main environmental impacts coming from the manufacturing, rather than the use phase.

The relative importance of the manufacturing versus use phase also varies depending on the assumptions about the energy mix during the use phase. An energy mix composed of higher renewable energy sources changes the dynamic of the impact, with increased renewable energy resulting in a decreased impact of the use phase and increasing the relative impact of the manufacturing stage, relative to the overall life cycle impact (Tähkämö 2013). The implication of this is that longer life lighting products might be even more important in the context of decarbonised energy mixes, as the increased relative impact from manufacturing implies using the product longer rather than shorter would be

\footnotetext{
${ }^{10}$ It should be noted that the differences are far less in considering energy impacts than considering other impacts related to waste, water pollution, resource efficiency, etc.
} 


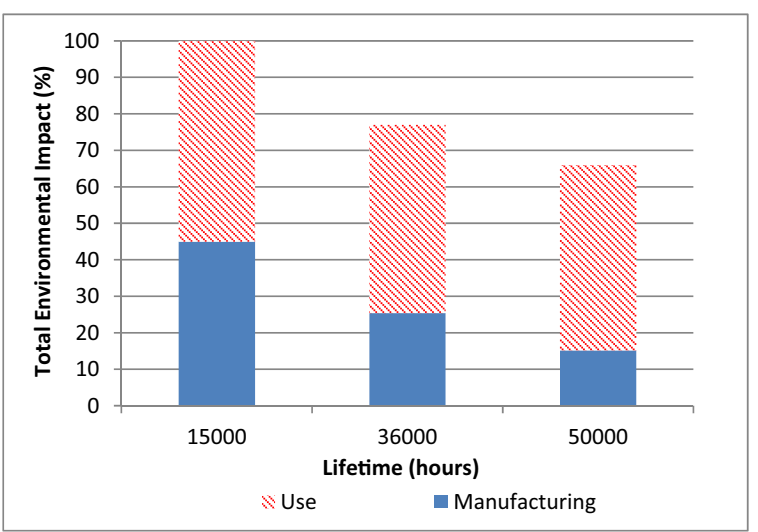

Fig. 3 Overall life cycle environmental impacts by life cycle phase and lifetime considered. Source: own, based on relative impact data from Tähkämö et al. (2013) (Note that transport and end of life were shown to have almost no effect on the overall environmental impacts, so these are omitted.)

desirable to allocate the manufacturing impacts over a longer functional lifetime.

However, these prior LCAs have considered lifetimes with the assumption of identical replacements products (i.e. products with a lifetime of 15,000 hours required three replacements identical to the first LED product to meet the same function as the LED product with a lifetime of 50,000 hours). In reality, consumers can replace shorter life products with newer, improved products. Scholand and Dillon's LCA study (2012) for the U.S. Department of Energy projected the efficacy for LED lamps would improve from 65 to $134 \mathrm{~lm} / \mathrm{W}$ from 2012 to 2017 and the 2017 LED lamp, which resulted in $50 \%$ less overall environmental impacts compared to the 2012 LED lamp. At the same time, there are also material developments to consider, for example, decreased use of aluminium for heat sinks, which can also decrease environmental impacts (e.g. Scholand and Dillon 2012). The study did not, however, consider then whether replacing the 2012 lamp before its lifetime of 25,000 hours would result in less environmental impact than continuing to use the 2012 lamp until the end of its lifetime.

Thus far, LCAs for LED lamps have not considered the question of optimal lifetimes taking into account improving LED lamps as replacements. Initial exploratory research using a scenario-based LCA approach indicated that there can be trade-offs between energyrelated and resource-related impacts (Richter et al. 2017). Such trade-offs would disappear as the technology matures (and the scenario becomes more akin to the identical replacements considered by earlier LCA studies of LED lamps). It is also therefore relevant to consider the projections for development of LED technology in assumptions about replacement scenarios (e.g. the maximum LED package efficacy is projected to increase up to $250 \mathrm{~lm} / \mathrm{W}$ by 2025 ; see U.S. Department of Energy 2013). Continued research developing the scenario-based LCA approach would be a complementary approach for determining optimal LED product lifetime to better understand the environmental benefits and trade-offs that may result from longer lifetimes. This would, in turn, inform the optimal timing of policies promoting longer lifetimes from an environmental perspective.

\section{Policy options for longer life LED products}

When it comes to LED lamps, the controversies surrounding the banning of traditional incandescent lamps and the mistrust of lighting regulations (cf. Sachs 2012) mean that it is paramount to set quality standards for new lighting technologies. Therefore, it is appropriate that there are minimum durability/lifetime standards currently set as a means to guarantee product quality and increase consumer confidence in LED lamps, which is important for uptake of LED lamps (Sandahl et al. 2014). The current mandatory standards for durability in the EU ecodesign regulations are shown in Table 2.

However, in comparison to the 6000 -h minimum, the analysis of a current LED market from an optimised LCC perspective suggest the optimal lifetime for household LED lamps is around 25,000 hours. Consumers may also expect longer minimum lifetimes for LED lighting products, since most of the LED lamps on the

Table 2 Ecodesign requirements for LED lamps related to durability and quality

\begin{tabular}{|c|c|}
\hline Lamp survival factor at 6000 hours & $\geq 90 \%$ \\
\hline Lumen maintenance at 6000 hours & $\geq 80$ \\
\hline $\begin{array}{l}\text { Number of switching cycles before } \\
\text { failure }\end{array}$ & $\begin{array}{l}\geq 15,000 \text { if rated lamp life } \\
\quad \geq 30,000 \text { hours, otherwise } \\
\quad \geq \text { half the rated lamp life } \\
\text { expressed in hours }\end{array}$ \\
\hline $\begin{array}{l}\text { Premature failure rate (maximum } \\
\text { number of failure products in } \% \text { ) }\end{array}$ & $\leq 5 \%$ at 1000 hours \\
\hline $\begin{array}{l}\text { Colour rendering requirements for } \\
\text { various applications }\end{array}$ & $\geq 80$ \\
\hline
\end{tabular}


market analysed claim lifetimes of at least 10,000 and up to 50,000 hours. Thus, minimum functionality requirements on lifetimes are lower than the optimal lifetimes and likely also lower than consumer expectations. Moreover, the transition of the lighting market towards LED lamps has meant a rapid improvement in durability of lighting products, with an increasing number of models in the market lasting longer periods and with good quality lighting output (Bennich et al. 2015).

If increased longer lifetimes are desirable, as the findings from modelling LCC in the market suggest, one way is to strengthen the minimum requirements in the ecodesign regulation. However, mandatory standards are not the only policy option and can have drawbacks; therefore, two other options are also considered: mandatory labelling and (mandatory or voluntary) customer warranties. These approaches each have their merits and limitations, which are discussed and summarised at the end of this section.

More ambitious mandatory ecodesign requirements

Generally, mandatory durability standards have benefits compared to the other policy options such as warranties and labelling. Firstly, it allows policymakers to make the appropriate trade-offs between different functions (e.g. energy use, technological developments and durability), based not only on optimal LCC but also technology assessments and LCAs. Secondly, the high complexity of establishing 'durability' for lighting, and the problems for consumers to understand information about durability, implies that mandatory requirements can be a good idea cf. to labelling and warranties.

The increasing importance of resource efficiency is likely to raise the relevance of more ambitious durability standards in the near future (not only for Circular Economy objectives, but also for climate policy objectives to address embodied emissions; see Scott et al. 2017). For example, long lifetimes can enable design where it is possible to repair, reuse and upgrade components or complete lighting solutions (Dzombak et al. 2017; Hendrickson et al. 2010). In turn, longer lifetimes may make efforts to design with modularity and standardisation more viable. These are currently challenging, but being discussed (see Gossart and Ozaygen 2016). While the LCC market analysis indicates a role for more ambitious standards, additional research is needed to examine optimal durability from an LCA perspective, where issues such as resource use and production phase impacts are part of the analysis.

In addition, practical methods for lifetime testing are required to implement and enforce any mandatory standards. In order to enforce such standards, there would need to be practical testing procedures (this applies also for labelling). Currently, standard testing methods consider the lifetime of the LED components rather than the whole system and often focus on lumen depreciation over catastrophic failure (i.e. complete non-functioning) though both are of concern (Narendran et al. 2016). Practical methods that can reliably predict the important sources of failure are a necessary first step in setting minimum standards. Such methods that stress test important parameters (e.g. switch cycles, change in temperature) and consider all important components in the lighting system (not only the LED but also e.g. drivers, solder between the LED and PCB, etc.) (Narendran et al. 2016). While these are promising developments in accelerated testing procedures (Narendran et al. 2016; Narendran, personal communication 3 March 2017), there may still be issues with how to establish test methods in legislation and the practical enforcement by member states.

Some jurisdictions like California are making requirements based on minimum rated lifetimes (and interestingly requiring longer lifetime minimums of 25,000 for higher intensity of use applications - in line with findings in this study) (California Energy Commission 2016). The IEA 4E SSL Annex also has voluntary performance standards with minimum rated lifetime requirements over 15,000 hours (in addition to 6000-h lumen maintenance and survival factor tests and endurance tests for switch cycles; see IEA 4E SSL Annex 2016). While development of an acceptable accelerated test is preferable, the currently available combination of LM80 measurements and TM21 extrapolation to assess the lifetime could be used in the interim as testing methods continue to be refined with new research and available data.

\section{Mandatory labelling}

Lifetime information is already required on lamp packaging, but not for specification in a label (i.e. the energy label). There is growing momentum in the EU to include durability requirements in mandatory energy labels, and this is an option that allows consumers to differentiate products not only in relation to energy efficiency but 
also durability. In the EU debate, there has been proposals that most products should be labelled with an 'average expected product lifetime', calculated through standardised methodologies, to allow better consumer decision-making (RREUSE 2015). Already today, energy labelling in the EU includes some non-energy-related information. One example is the label for vacuum cleaners, as it is a multi-dimensional label, where mandatory information includes energy rating, annual energy use, emission (dust in exhaust air), noise level, pickup performance for carpets and pickup performance for hard floors.

However, there is some general concern regarding the design of energy labelling and how consumers interpret the energy efficiency information (Molenbroek et al. 2014; Waechter et al. 2015) that implies it can be difficult to also include information on expected lifetime. The first question is whether the producer should account for minimum lifetime, or expected lifetime of the product, and how the choice of parameter can be communicated in an easy-to-understand fashion to consumers. Further, as discussed previously, lifetime entails many dimensions in the case of lighting. It is not realistic to expect consumers to understand all of them, nor to have information about all of them on the product (i.e. expected lifetime in terms of acceptable luminous flux, expected lifetime for acceptable colour rendering, etc.). One potential way forward is that the labelling regulation stipulates a minimum for all these categories and that the expected lifetime indicated by the producer implies that all these dimensions are fulfilled to satisfactory level during the indicated lifetime. For most LED applications, it is primarily lumen output that matters, so lumen depreciation could be a potential first category to include in labelling.

Generally speaking, the issue of whether and how consumers react to labelling is quite complex (see e.g. Waechter et al. 2015; Dalhammar et al. 2018). For example, there are indications that this partly depends on the product group, as consumers are more likely to consider energy labelling for some product purchases than others. Research on consumer behaviour with LED products has also shown energy efficiency does not motivate many consumers (Rodemeier et al. 2017), so it is unclear how consumers will act upon durability information for lighting products. Further, consumers have an easier time understanding some information provided in energy labels than others. Most notably, consumers understand the information provided on what energy class an appliance belongs to (in Europe this is presented through letters, with ' $\mathrm{A}$ ' being the bestperforming category), but often do not understand other types of information provided through the labelling such as information on expected annual energy use (Waechter et al. 2015). Furthermore, there are indications that the European practice of updating standards through adding additional plus signs to the letters (e.g. 'A+' and 'A++') is confusing (Dalhammar et al. 2018).

The main advantage of using labelling to communicate lifetime is that it allows consumers to choose products according to preferences and provides for competition in the market. The main disadvantage is that there may be incentives to cheat for producers as there are challenges related to market monitoring and product testing. Further, the wide range of products and applications may imply that it is hard to put a meaningful number for the expected lifetime in all cases, as LEDs are often integrated into various systems (Next Generation Lighting Industry Alliance 2014).

Warranties and guarantees

Another possible option for ensuring the lifetime of LED lamps is extended guarantees or warranties. A warranty is a term of a contract, breach of which gives rise to a claim for damages, but (usually) not the repudiation of the whole contract. Such warranties can be pursued either through mandated warranty periods, or through voluntary warranties. As a baseline, consumers in most jurisdictions have a legally mandated warranty for a certain period of time, often ranging from 1 to 3 years. Both in the EU and the USA, there are different rules in different jurisdictions related to warranties for consumers. Some jurisdictions such as Iceland and Norway also provide consumer rights for nonconforming products for a longer period of 5 years when the products are meant to last for a considerably longer time (Tonner and Malcolm 2017). It should be noted that it is not only the general warranty that is of importance; in some jurisdictions, producers' claims about lifetime could lead to a consumer claim if the product falls short of its indicated lifetime, as this can constitute a breach of satisfactory quality (Stone 2015).

It is not only the length of the warranty per se that is of importance, but also other factors, most notably when the burden of proof for showing that a product defect was present at the time of purchase is transferred from seller to buyer, as this can be difficult to prove. In most 
EU countries, this burden of proof is moved from the seller to the buyer after 6 months. The EU NGO RREUSE has proposed that products can be more durable and repairable if the burden of proof lies with the seller/manufacture for 2 years instead of 6 months, and that this can be enforced through higher "Mean Time Between Failure (MTBF)" requirements for critical subassemblies such as those with electromechanical parts/ components (RREUSE 2015).

EU law on consumer protection is a mix of acts that aim at minimum harmonisation and acts that aim at total harmonisation. The main benefits of minimum harmonisation are that it secures minimum rights for the consumer while allowing Member States to strengthen consumer protection. The main drawback is that practices in EU Member States differ, which forces producers to adopt different business practices throughout the EU (Mańko 2015).

Whether warranties actually provide incentives for durability depends on the circumstances. When it comes to LED lamps, the rather limited cost of the product and its longevity may mean that consumers do not pursue a warranty claim, e.g. because the reward is limited compared to the effort. And, consumers may be suspicious towards warranty claims from firms that may be on the market only temporarily (Price and Dawar 2002). Industry associations seem to view the use of warranties, reliability claims, etc., as good source of information for customers (Next Generation Lighting Industry Alliance 2014), but in reality, this mainly applies to professional users as private consumers cannot be expected to understand this information and assess its validity.

Generally, for most products groups, there are indications that EU companies prefer ecodesign requirements setting mandated minimum lifetime in hours, to mandated extended warranties in years (Dalhammar 2016). The reasons are likely that (1) guaranteeing lifetime in hours rather than years protects the producers from intensive product use by consumers and (2) mandated long warranty times undermine the lucrative business of selling longer warranties to consumers (Dalhammar 2016). Also for LED lamps, providing warranties in hours (in use) rather than years appears most suitable (Next Generation Lighting Industry Alliance 2014).

For professional users, there is the option for producers to voluntarily offer extended warranties that include both replacements of faulty products and other services such as maintenance. The buyers can then chose a contract that suits their risk preferences and the technical installation. It is doubtful if a mandated warranty should be legislated for B2B relations, as the LED lamps can be used for many different purposes. Regarding mandatory warranties for consumers, it is also doubtful if LED guarantees going beyond what is provided through general consumer protection legislation should be implemented, although such warranties could further improve consumer confidence in LED products.

\section{Summary of options for increased durability}

Table 3 gives a summary of the advantages and disadvantages of different policy approaches. While this study and other LCC studies suggest a role for policy to promote longer lifetimes to achieve optimal durability and optimal LCC, there can also be arguments against such policies. The regulation stipulating functionality requirements stated that their aim is "to ensure consumer satisfaction with energy-saving lamps, in particular LEDs..."11 It has been argued that domestic consumers are not usually interested in very durable products; whereas, professional buyers can make use of warranties when they want durable LED lamps (cf. Next Generation Lighting Industry Alliance 2014). This would imply that more policy drivers for inducing increased durability for lighting products are not necessary or desirable. While research in the USA has found that consumers do value durability as an attribute for lighting products, with stated willingness to pay more between 0.52 and 0.66 USD for every 1000 -h increase in lifetime (Min et al. 2014), the purchase price of LED lamps has decreased dramatically in recent years, which call into question again the perceived value of longer lifetimes for consumers.

Another argument is that manufacturers are already selling LED lamps highlighting long-life LED products to consumers who value this, and this could in itself push the market towards increased durability without policy. At the same time, there is speculation about planned obsolescence for LED lighting products (MacKinnon 2016). The U.S. Department of Energy market analysis of LED lamps shows that there can be

\footnotetext{
${ }^{11}$ Commission Regulation (EU) No 1194/2012 of 12 December 2012 implementing Directive 2009/125/EC of the European Parliament and of the Council with regard to ecodesign requirements for directional lamps, light emitting diode lamps and related equipment, at (15)
} 
Table 3 Summary of options for increased durability requirements

\begin{tabular}{|c|c|c|}
\hline Policy choice & Advantages & Disadvantages \\
\hline Mandatory requirements & $\begin{array}{l}\text { Allows policymakers to make the appropriate } \\
\text { trade-offs between different functions } \\
\text { (e.g. energy use, technological developments } \\
\text { and durability) } \\
\text { The complexity of establishing 'durability' for } \\
\text { lighting, and the problems of consumers } \\
\text { to understand information about durability, } \\
\text { implies that mandatory requirements can be } \\
\text { a good idea cf. to labelling and warranties }\end{array}$ & $\begin{array}{l}\text { By setting durability standards that goes further } \\
\text { than a mere 'baseline', policymakers may } \\
\text { interfere with decisions that are best taken } \\
\text { by designers, based on customer needs } \\
\text { and user patterns } \\
\text { May be better to let customers use labelling } \\
\text { to differentiate product lifetime according } \\
\text { to their preferences }\end{array}$ \\
\hline Mandatory labelling & $\begin{array}{l}\text { Allows consumers to choose products according } \\
\text { to preferences and provides for competition } \\
\text { in the market } \\
\text { Less intrusive for producers than mandatory } \\
\text { lifetime requirements }\end{array}$ & $\begin{array}{l}\text { Difficult for consumers to understand/ interpret } \\
\text { the information } \\
\text { Risk of cheating } \\
\text { The broad range of LED products and applications } \\
\text { can lead to quite varying definitions of lifetimes }\end{array}$ \\
\hline Voluntary extended warranties & $\begin{array}{l}\text { Useful in B2B applications where buyers can } \\
\text { interpret technical information and enter } \\
\text { into relevant contracts that are suitable for the } \\
\text { purpose where the LED products are used }\end{array}$ & $\begin{array}{l}\text { Less useful for private buyers as the information } \\
\text { is complex and the limited price of many LED } \\
\text { products may mean that buyers are not very interested }\end{array}$ \\
\hline $\begin{array}{l}\text { Mandatory extended } \\
\text { warranties }\end{array}$ & $\begin{array}{l}\text { Could be useful for consumers and } \\
\text { increase confidence in LED products }\end{array}$ & Not so useful in B2B relations \\
\hline
\end{tabular}

a range of design choices for LED lamps and they can be designed with or without trade-offs between different parameters, including energy efficiency and lifetimes (U.S. Department of Energy, Solid-State Lighting Program 2016). In light of environmental policies often having both energy and resource efficiency aims (the latter of increasing importance in the context of circular economy goals), such trade-offs should be avoided and optimising both energy and resource efficiency encouraged. Thus, policy addressing lifetimes may be relevant to ensure environmental benefits from longer lifetimes are realised in practice.

\section{Conclusions and recommendations}

This paper has demonstrated how modelling the relationship between LCC and PWF can approximate optimal lifetimes for the product market being considered. The optimum lifetimes for the LED lamp market considered was indicated by the analysis to be higher (approximately 25,000 hours) than the market average for lifetime $(21,500)$, suggesting there is likely a role for durability policies to move the market closer to its LCC optimum. The analysis also indicated that longer lifetimes are important when smaller discount rates and more intensive use of a product are factors, suggesting LED lamps typical in intense-use applications of LED lamps should be the initial policy focus. There was also found to be a relationship in optimised LCC between longer lifetimes and lower energy use. The method presented in this paper can be useful for determining and monitoring optimal durability as part of tracking attributes and LCC in a product market. Further research can investigate optimal lifetimes for other products to compare to the case of LED lamp products presented in this paper.

The findings in this case motivate further investigation into the feasibility of setting more stringent lifetime requirements for LED lamps. It is recommended that the LCC approach adopted in this study is complemented by an LCA approach that also determines the environmental impacts of lifetimes and replacement scenarios for LED lamps, considering the context of continued development of LED technology and markets, to determine the appropriate timing for promoting durability from an environmental perspective. The paper discussed promoting durability through different types of policies, which have different advantages and drawbacks. Increasing stringency of lifetime requirements for the case of LED lamps also requires implementation of accelerated testing methods to ensure such standards can be practically enforced. Overall, it is recommended 
that lifetime continues to be addressed first and foremost by minimum performance standards, but there is also a role for development of better labelling and warranties for these products in terms of durability.

Acknowledgements We gratefully thank Kasper Mogensen from Big2Great (big2great.dk) for his assistance with the web crawled data for LED lamps. This research was first presented and discussed at the 2017 ECEEE Summer Study. Lastly, we thank the peer reviewers for their valuable and constructive comments that further improved this paper.

Funding information This research was financially supported by the Swedish Energy Agency (Energimyndigheten) through the project 'Promoting ecodesign for the advancement of innovation, competitiveness and environmental improvements' (grant no. 36936-1). Jessika Luth Richter's research was also financially supported by the EU-Interreg project 'Lighting Metropolis'.

\section{Compliance with ethical standards}

Conflict of interest The authors declare that they have no conflict of interest.

Open Access This article is distributed under the terms of the Creative Commons Attribution 4.0 International License (http:// creativecommons.org/licenses/by/4.0/), which permits unrestricted use, distribution, and reproduction in any medium, provided you give appropriate credit to the original author(s) and the source, provide a link to the Creative Commons license, and indicate if changes were made.

\section{References}

Bakker, C., Ingenegeren, R., Devoldere, T., Tempelman, E., Huisman, J., \& Peck, D. (2012). Rethinking eco-design priorities; the case of the Econova television. In 2012 Electronics Goes Green 2012+ (pp. 1-7).

Bakker, C., Wang, F., Huisman, J., \& den Hollander, M. (2014). Products that go round: exploring product life extension through design. Journal of Cleaner Production, 69, 10-16. https://doi.org/10.1016/j.jclepro.2014.01.028.

Bennich, P., Soenen, B., Scholand, M., \& Borg, N. (2015). Updated test report-clear, non-directional LED lamps. Retrieved from https://www.energimyndigheten.se/Global/F\%C3\%B6 retag/Ekodesign/Produktgrupper/Belysning/Report\%20on\%20 Testing\%20of\%20Clear\%20LED\%20lamps\%20v5\%205.pdf.

Bennich, P., Stengård, L., Christensen, S. F., Hartikainen, T., Mogensen, K., \& Larsen, T. F. (2017). Using webcrawler techniques for improved market surveillance- new possibilities for compliance and energy policy. Presented at the ECEEE Summer Study. Retrieved from https://www.eceee. org/library/conference_proceedings/eceee_Summer_ Studies/2017/7-appliances-products-lighting-and-ict/using- webcrawler-techniques-for-improved-market-surveillance8211-new-possibilities-for-compliance-and-energy-policy/.

Boulos, S., Sousanoglou, A., Evans, L., Lee, J., King, N., Facheris, C., ... Donelli, M. (2015). The durability of products: standard assessment for the circular economy under the EcoInnovation Action Plan. Report for European Commission, DG Environment.

Burrows, D. (2016). UBA calls for product resource efficiency policies. ENDS Europe. Retrieved from http://www. endseurope.com/article/45200/uba-calls-for-productresource-efficiency-policies.

California Energy Commission. (2016). Energy commission adopts lighting standards to save Californians more than $\$ 4$ billion in electricity costs. Retrieved from http://www.energy. ca.gov/releases/2016_releases/2016-01-27_adoption_of_ lighting_standards nr. $\bar{h}$ tml.

Casamayor, J., Su, D., \& Sarshar, M. (2015). Extending the lifespan of LED-lighting products. Architectural Engineering and Design Management, 11(2), 105-122. https://doi.org/10.1080/17452007.2013.834813.

Casamayor, J. L., Su, D., \& Ren, Z. (2017). Comparative life cycle assessment of LED lighting products. Lighting Research \& Technology, (0), 1-26. https://doi.org/10.1177 /1477153517708597.

Cooper, D. R., \& Gutowski, T. G. (2015). The environmental impacts of reuse: a review. Journal of Industrial Ecology. https://doi.org/10.1111/jiec.12388.

Dalhammar, C. (2016). Industry attitudes towards ecodesign standards for improved resource efficiency. Journal of Cleaner Production, 123, 155-166.

Dalhammar, C., Richter, J. and Machacek, E. (2018). Energy efficiency regulations, market and behavioural failures, and standardization. In. Maitre-Ekern, E., C. Dalhammar \& H.C. Bugge. (Eds.). Preventing environmental damage from products-analyses of the policy and regulatory framework in Europe. (pp. 176-228). Cambridge University Press.

Dzombak, R., Padon, J., Salsbury, J., \& Dillon, H. (2017). Assessment of end-of-life design in solid-state lighting. Environmental Research Letters, 12(8), 084013. https://doi. org/10.1088/1748-9326/aa7ab1.

ENDS. (2016). UBA Calls for Product Resource Efficiency Policies. ENDS Europe Daily (17 February 2016).

EU Commission. (2015). Evaluation of the Energy Labelling and Ecodesign Directives (Commission staff working documents). EU Commission. Retrieved from https://ec.europa. eu/energy/sites/ener/files/documents/1_EN_autre document_travail_service_part1_v2.pdf.

European Commission. (2016). Circular economy strategy. Retrieved 3 January 2017, from http://ec.europa. eu/environment/circular-economy/index en.htm.

European Parliament. (2017). Report on a longer lifetime for products: benefits for consumers and companies. (2016/2272(INI)). Committee on the Internal Market and Consumer Protection. Rapporteur: Pascal Durand.

Gerke, B. F., Ngo, A. T., \& Fisseha, K. S. (2015). Recent price trends and learning curves for household LED lamps from a regression analysis of internet retail data. Berkeley, CA: Lawrence Berkeley National Laboratory. Retrieved from https://ees.lbl.gov/sites/all/files/lbnl-184075.pdf.

Gossart, C., \& Ozaygen, A. S. (2016). Lighting transition: overcoming barriers to eco-innovation in the LED sector. 
Presented at the 7th International Sustainability Transitions (IST) Conference, Wuppertal. Retrieved from https://ist2016. org/fa/ist2016/downloads/IST2016_book_of_abstracts.pdf.

Gutowski, T. G., Sahni, S., Boustani, A., \& Graves, S. C. (2011). Remanufacturing and energy savings. Environmental Science \& Technology, 45(10), 4540-4547. https://doi. org/10.1021/es102598b

Hendrickson, C. T., Matthews, D. H., Ashe, M., Jaramillo, P., \& McMichael, F. C. (2010). Reducing environmental burdens of solid-state lighting through end-of-life design. Environmental Research Letters, 5(1), 014016.

Hixon, T. (2012). LED light bulbs mature at last. Forbes Retrieved from https://www.forbes.com/sites/toddhixon/2012/12/13 /led-light-bulbs-mature-at-last/.

IEA 4E SSL Annex (2016) Solid state lighting annex: product quality and performance tiers. Retrieved from https://ssl.iea4e.org/files/otherfiles/0000/0094/1_-_Task_6_-_NonDirectional_Lamps_Tiers_-_Final___Nov2016.pdf.

MacKinnon, J. B. (2016, July 14). The L.E.D. Quandary: why there's no such thing as 'built to last'. The New Yorker Retrieved from http://www.newyorker. $\mathrm{com} /$ business/currency/the-1-e-d-quandary-why-theres-nosuch-thing-as-built-to-last.

Maitre-Ekern, E., \& Dalhammar, C. (2016). Regulating planned obsolescence: a review of legal approaches to increase product durability and reparability in Europe. Review of European, Comparative \& International Environmental Law, 25(3), 378-394. https://doi.org/10.1111/reel.12182.

Mańko, R. (2015). Methods for unifying private law in the EU. EPRS Briefing, (130628REV1). Retrieved from http://papers.ssrn.com/sol3/papers.cfm?abstract_ id $=2674645$.

Min, J., Azevedo, I. L., Michalek, J., \& de Bruin, W. B. (2014). Labeling energy cost on light bulbs lowers implicit discount rates. Ecological Economics, 97, 42-50. https://doi. org/10.1016/j.ecolecon.2013.10.015.

Molenbroek, E., Smith, M., Groenenberg, H., Waide, P., Attali, S., Fischer, C., Krivosik, J., Fonseca, P, Santos, B., Fong, J. (2014). Evaluation of the Energy Labelling Directive and specific aspects of the Ecodesign Directive. Final Technical Report. ENER. C3/2012-523. ECOFYS. Retrieved from http://www.energylabelevaluation.eu/tmce/Final_technical_ report-Evaluation_ELD_ED_June_2014.pdf

Montalvo, C., Peck, D., \& Rietveld, E. (2016). A longer lifetime of products: benefits for consumers and companies. Study for Internal Market and Consumer Protection (IMCO) Committee; European Parliament: Brussels, Belgium. Retrieved from http://www.europarl.europa.eu/RegData/etudes/STUD/2016 1579000/IPOL_STU(2016)579000_EN.pdf.

Narendran, N., Liu, Y., Mou, X., Thotagamuwa, D. R., \& Eshwarage, O. V. M. (2016, September). Projecting LED product life based on application. In Fifteenth International Conference on Solid State Lighting and LEDbased Illumination Systems. (Vol. 9954, p. 99540G). International Society for Optics and Photonics. https://doi.org/10.1117 /12.2240464.

Navigant. (2016). Energy savings forecast of solid-state lighting in general illumination applications. U.S. Department of Energy. Retrieved from https://energy.gov/sites/prod/files/2016/09/f33 /energysavingsforecast16_2.pdf.
Next Generation Lighting Industry Alliance. (2014). LED Luminaire Lifetime: recommendations for testing and reporting (No. 3). Retrieved from http://www.nglia. $\mathrm{org} / \mathrm{pdfs} /$ led_luminaire_lifetime_guide_sept2014.pdf.

Ochs, K. S., Miller, M. E., Thal, A. E., \& Ritschel, J. D. (2014). Proposed method for analyzing infrastructure investment decisions involving rapidly evolving technology: case study of LED streetlights. Journal of Management in Engineering, 30(1), 41-49. https://doi.org/10.1061/(ASCE)ME.19435479.0000177 .

Prakash, S., Dehoust, G., Gsell, M., Schleicher, T., \& Stamminger, R. (2015). Einfluss der Nutzungsdauer von Produkten auf ihre Umweltwirkung: Schaffung einer Informationsgrundlage und Entwicklung von Strategien gegen „Obsoleszenz “: ZWISCHENBERICHT: Analyse der Entwicklung der Lebens-, Nutzungs-und Verweildauer von ausgewählten Produktgruppen. Z Ischenbericht: Nalyse Der Ent Icklung Der Lebens-, Nutzungsund Verweildauer von Ausgewählten Produktgruppen. UBA-Texte, 10, 2015.

Price, L. J., \& Dawar, N. (2002). The joint effects of brands and warranties in signaling new product quality. Journal of Economic Psychology, 23(2), 165-190. https://doi. org/10.1016/S0167-4870(02)00062-4.

Richter, J. L., Dalhammar, C., \& Tähkämö, L. (2017). Considering optimal lifetimes for LED lamps: a mixed approach and policy implications. Presented at the Product Lifetimes and the Environment (PLATE), TU Delft.

Rodemeier, M., Löschel, A., \& Kube, R. (2017). Casting light on energy efficiency: evidence on consumer inattention and imperfect information. Applied Economics Letters, 1-13. https://doi.org/10.1080/13504851.2017.1332742.

RREUSE. (2015). Improving product reparability: policy options at the EU level. Retrieved from http://www.rreuse.org/wpcontent/uploads/Routes-to-Repair-RREUSE-final-report. pdf.

Sachs, N. M. (2012). Can we regulate our way to energy efficiency: product standards as climate policy. Vand. $L$. Rev., 65, 1631. https://www.law.cornell.edu/citation/4700

Sandahl, L. J., Cort, K. A., \& Gordon, K. L. (2014). Solid-state lighting: early lessons learned on the way to market. U.S. Department of Energy. Retrieved from https://www1.eere. energy.gov/buildings/publications/pdfs/ssl/ssl_lessonslearned_2014.pdf.

Scholand, M., \& Dillon, H. E. (2012). Life-cycle assessment of energy and environmental impacts of LED lighting products part 2: LED manufacturing and performance. Pacific Northwest National Laboratory (PNNL), Richland, WA (US). Retrieved from http://www.osti. gov/scitech/biblio/1044508.

Scott, K., Roelich, K., Owen, A., \& Barrett, J. (2017). Extending European energy efficiency standards to include material use: an analysis. Climate Policy, 18(5), 627-641. https://doi. org/10.1080/14693062.2017.1333949.

Siderius, H.-P. (2013). The role of experience curves for setting MEPS for appliances. Energy Policy, 59, 762-772. https://doi.org/10.1016/j.enpol.2013.04.032.

Stone, P. (2015). Do you know where you stand if an LED product fails early? [Industry]. Retrieved from http://luxreview. com/article/2015/04/promises-promises. 
Tähkämö, L. (2013). Life cycle assessment of light sources - case studies and review of the analyses. Aalto University. Retrieved from https://aaltodoc.aalto.fi/handle/123456789 $/ 10905$

Tähkämö, L., \& Dillon, H. (2017). Life cycle assessment of lighting technologies. In R. Karlicek, C.-C. Sun, G. Zissis, \& R. Ma (Eds.), Handbook of advanced lighting technology (pp. 935-956). Cham: Springer International Publishing. https://doi.org/10.1007/978-3-319-00176-0_41.

Tähkämö, L., Bazzana, M., Ravel, P., Grannec, F., Martinsons, C., \& Zissis, G. (2013). Life cycle assessment of light-emitting diode downlight luminaire - a case study. The International Journal of Life Cycle Assessment, 18(5), 1009-1018.

Tähkämö, L., Räsänen, R.-S., \& Halonen, L. (2016). Life cycle cost comparison of high-pressure sodium and light-emitting diode luminaires in street lighting. The International Journal of Life Cycle Assessment, 21(2), 137-145.

Tonner, K., \& Malcolm, R. (2017). How an EU lifespan guarantee model could be implemented across the European Union. European Parliament, Citizens' Rights and Constitutional Affairs. Retrieved from http://www.europarl.europa. eu/RegData/etudes/STUD/2017/583121/IPOL_STU(2017 )583121_EN.pdf.

U.S. Department of Energy. (2013). Energy efficiency of LEDs. Retrieved from http://www.hi-led.eu/wpcontent/themes/hiled/pdf/led_energy_efficiency.pdf.

U.S. Department of Energy, Solid-State Lighting Program. (2016). Solid-state lighting R\&D plan (No. DOE/EE-1418). Retrieved from https://energy.gov/sites/prod/files/2016/06 /f32/ss1_rd-plan_\%20jun2016_2.pdf.

Van Buskirk, R. D. (2015). Real-time efficient product market monitoring from the perspective of a private-sector efficient product marketplace operator. Presented at the Real-Time Tools for 21st
Century EE Standards, Labels and Programs, IEA. Retrieved from https://www.iea.org/media/workshops/2015 /productsdec 15 -16/3.4_RobertvanBuskirk_ RealtimeEfficientProductMarketMonitoring.pdf.

Van Buskirk, R.D., \& Richter, J. L. (2017). Dataset for 'Optimal Lifetimes in Life Cycle Cost Methods': the case of LED lamps. Retrieved from http://lup.lub.lu.se/record/38396fde0b7f-411d-8254-3088a49cc8d2.

Van Buskirk, R. D., Kantner, C. L. S., Gerke, B. F., \& Chu, S. (2014). A retrospective investigation of energy efficiency standards: policies may have accelerated long term declines in appliance costs. Environmental Research Letters, 9(11), 114010. https://doi.org/10.1088/1748-9326/9/11/114010.

VHK. (2014). Resource efficiency requirements in ecodesign: review of practical and legal implications. Ministerie van Infrastructuur en Millieu. Retrieved from http://kunststofkringloop.nl/wp-content/uploads/2016/01 /Ecodesign-Resource-Efficiency-FINAL-VHK-20141120.pdf.

VITO, \& VHK. (2015a). Preparatory study on light sources for ecodesign and/or energy labelling requirements. Final report, task 5: environment \& economics (base case LCA \& $L C C$ ). European Commission. Retrieved from http://ecodesign-lightsources.eu/sites/ecodesignlightsources.eu/files/attachments/LightSources\%20Task7 \%20Final\%2020151031.pdf.

VITO, \& VHK. (2015b). Preparatory study on light sources for ecodesign and/or energy labelling requirements. Final report, task 7: scenarios. European Commission. Retrieved from http://ecodesign-lightsources.eu/sites/ecodesignlightsources.eu/files/attachments/LightSources\%20Task7 \%20Final\%2020151031.pdf.

Waechter, S., et al. (2015). Desired and undesired effects of energy labels - an eye-tracking study. PLoS One, 10(7), 1-26. 